\title{
FEMALE CONSUMERS' APPAREL DISPOSAL BEHAVIOUR IN THE SOUTH AFRICAN EMERGING MARKET CONTEXT
}

\author{
NADINE CYNTHIA SONNENBERG, JOHANNA MARIA MAGDALENA MARX-PIENAAR \\ \& MARIA JACOBA STOLS \\ Department of Consumer and Food Science, University of Pretoria, South Africa
}

\begin{abstract}
The apparel supply chain's contribution toward pollution, natural resource depletion and excessive waste is cause for much concern. Sustainable strategies should form part of the entire apparel life cycle, but also more specifically the disposal stage, during which consumers should be encouraged to adopt waste reduction behaviours such as donating, recycling and/or reselling unwanted apparel. To date, this topic has received limited attention in developing countries such as South Africa, where disadvantaged communities are most adversely affected by environmental deterioration and overflowing landfills. This study thus aimed to explore and describe female consumers' intent to dispose of apparel in a more sustainable manner within the local South African context. The non-probable sampling procedure purposively focused on females, because they tend to make the primary decisions regarding households' unwanted apparel. A structured, self-administered web-based questionnaire was developed. Scale items were derived from prior empirical research, yet adapted and pre-tested to comply with local conditions. Responses were measured on a five point Likert type scale. The eventual sample consisted of 315 females between the ages of 18 and 65 years, who resided in the geographical scope of Gauteng, South Africa. Most respondents had some form of tertiary education $(65 \%)$ and belonged to middle-income levels (54\%). Exploratory factor analysis was conducted to reveal three factors, namely respondents' intent to donate $(\mathrm{M}=4.36)$, resell $(\mathrm{M}=3.84)$ and reuse/recycle apparel $(\mathrm{M}=4.05)$. The findings provide insight pertaining to respondents' willingness to donate, perhaps more so than their inclination to resell or reuse unwanted apparel, due to various contextual circumstances. This may offer a basis for the development of waste reduction campaigns and intervention strategies in the apparel domain and direct future investigation in other emerging markets to establish consumers' willingness to engage in sustainable apparel disposal behaviour.
\end{abstract}

Keywords: textile waste, apparel disposal, clothing reuse, consumer behaviour, emerging economy.

\section{INTRODUCTION}

Poor waste management has detrimental environmental effects and has for these reasons, been the topic of several studies conducted in more developed countries [1]. To date less empirical evidence has focused on the disposal of products in developing countries such as South Africa, despite the fact that disadvantaged communities in these countries are at greater risk and are more negatively influenced by environmental deterioration that result from poor waste management [1]. Certain areas in Africa have in fact been ranked among the most unhealthy environments to live in [2] with ecosystems that are rapidly changing due to global and local pressure for economic advancement [3]. It has further been established that developing countries such as Kenya and, for that matter, South Africa, tend to have waste that is heavier, wetter, and more detrimental than is the case elsewhere in the world [4]. This is because waste in developing countries is not yet fully appraised, owing to limited environmental control systems [5] and dumpsites that are plagued with poor infrastructure, uncontrolled and indiscriminate dumping, pollution and health risks [6]. Urgent measures are thus needed to prevent further environmental deterioration that result from the disposal of waste in general, but also more specifically apparel waste. 
In recent years the textile and apparel industry has come under severe scrutiny because of detrimental environmental consequences associated with the manufacturing, sales, distribution, and use of apparel. The apparel supply chain is, in fact, recognised as one of the most harmful polluters worldwide with particular concern related to the excessive amounts of industrial wastewater that is generated as a result of apparel production [7]. In Nigeria alone, the apparel and textile industry contributes to $37,727,890 \mathrm{~kg}$ emission per year which severely pollutes local water resources [8]. Fast fashion retailing is further identified as a root cause for superfluous supply of cheap garments, which are indiscriminately discarded on a regular basis to make way for the latest trends [9]. This is particularly alarming because the disintegration of textiles encompasses immense environmental challenges due to leachate percolation [10]. Stringent effort is thus needed to reduce the textile industry's environmental footprint from the initial raw materials production through to the disposal of products with specific emphasis directed toward the importance of sustainable and environmentally responsible disposal behaviour among apparel consumers [11].

Consumers can dispose of apparel in a number of ways, including donating, reselling, reusing/recycling or discarding. Discarding refers to simply throwing unwanted waste into trash that ends up in municipal landfills [12]. Consumers, in preferring a faster and more convenient method of disposing their used or unwanted apparel, often choose to discard apparel rather than to engage in other more eco-friendly alternatives [11]. As mentioned before, textile waste that ends up in landfills has an enormous effect on the environment and needs to be reduced [10]. A more eco-friendly alternative, whereby the lifespan of the garment is extended, includes donation. Donating apparel refers to giving unwanted clothing to family and friends, or to the needy in order to help them [9]. Recycling and reusing refers to using apparel again for the same or a different purpose [13]. Consumers can also resell unwanted apparel, which may entail environmental and financial benefits [11].

Despite its relevance, the disposal of apparel and clothing remains an understudied topic (especially in developing countries) with most of the effort to date centred on the disposal of other substances such as plastic, glass, and paper [13]. This research was therefore specifically focused on exploring and describing female consumers' intent, to dispose of apparel in a more eco-friendly manner (including the recycling/reusing, reselling and donation) in the local South African context. Female consumers' behaviour is of particular interest because women tend to be the principal role players in households' decisions regarding clothing [14]. They also tend to be more environmentally concerned with a proenvironmental inclination regarding the purchase and disposal of apparel [15].

\section{METHOD}

This study followed an exploratory descriptive approach to generate an initial basis of understanding surrounding female consumers' apparel disposal behaviour in the South African emerging market context. To date there has been limited empirical evidence regarding the topic in question. It should be noted that the study's cross-sectional survey design captured the responses of a specific group of females at one point in time and can therefore not account for their behaviour over an extended period of time.

\subsection{Sample and sampling}

A non-probability sampling technique was used to purposively recruit female consumers who were all above the age of 18 and who made decisions regarding the acquisition, use, and disposal of apparel. Previous studies [14], [15], for example, reveal that women tend to have a stronger attitude and set behaviour regarding the environment than males. The eventual 
sample $(\mathrm{N}=315)$ consisted of female consumers who resided in Gauteng, which is a major metropolitan region in South Africa. Most respondents were White, had some form of tertiary education (65\%) and belonged to middle-income levels (54\%). Although the non-probability sampling procedures clearly limit the generalisability of results, the sample was nevertheless deemed appropriate in gaining preliminary insights into the topic at hand.

\subsection{Data collection}

A self-administrated web-based survey questionnaire was developed to deliver quantitative data that could be translated into statistical analysis. Scale items were derived from previous empirical research [12], yet adapted to the purposes of this study. Twelve items were included to measure respondents' willingness to engage in each of the eco-friendly disposal options i.e. donation, reselling and reusing. Responses were anchored on a 5 point Likert scale ranging from 1 (strongly disagree) to 5 (strongly agree). A pilot study was conducted to ensure that question wording was understandable and to eliminate potential errors prior to the main data collection procedures. The final questionnaire was distributed via the Qualtrics web-based software, which resulted in 315 successfully completed responses $(\mathrm{N}=315)$. The data were electronically captured and coded for further statistical analysis.

\section{RESULTS AND DISCUSSION}

An exploratory factor analysis (EFA) was conducted by means of SPSS software, employing Varimax rotation with Kaiser Normalization. These procedures were followed to uncover relevant factors (i.e. constructs) from the dataset. Taking into account Kaiser's criteria (i.e. all factors with an eigenvalue $>1$ should be retained) in addition to the point of inflexion on the scree plot, a three factor solution was deemed appropriate. No items were eliminated. The results of the EFA is reported in Table 1. As can be gathered from Table 1, items that converged under each factor clearly aligned to a particular disposal method. The factors were consequently labelled as follows: Factor 1: Resell, Factor 2: Reuse and Factor 3: Donate.

All three factors achieved high Cronbach's Alpha, indicating internal consistency of responses and substantiating the reliability of the measuring instrument. Furthermore, the mean for donate $(\mathrm{M}=4.36)$ was higher than the means for the other disposal options. In this regard it should be noted that South Africa, as a developing country, has a large proportion of disadvantaged and less fortunate consumer segments. In general, South Africans may thus feel obligated to donate their unwanted clothing to charities to help the less fortunate. In summary, respondents' willingness to donate could be fuelled by altruistic underpinnings that extend beyond pro-environmental intent.

\section{CONCLUSION AND FUTURE RESEARCH RECOMMENDATIONS}

Without the necessary behavioural changes, environmental damage that is caused by poor waste management will intensify [16]. Strategies employed by government and other relevant stakeholders are important, yet consumers' role in waste reduction initiatives are equally definitive and therefore it is important to understand their willingness to engage in various disposal methods. In this study, respondents' willingness to donate unwanted apparel may be attributed to the prevalence of charitable causes and needy communities in the local context. It is however argued that the inclination to resell or reuse apparel could also be further harnessed in the local domain by creating more facilitating opportunities for such behaviour e.g. placing recycling bins in apparel retail outlets. 
Table 1: Exploratory factor analysis.

\begin{tabular}{|l|c|c|c|}
\hline \multirow{2}{*}{\multicolumn{1}{|c}{$\begin{array}{c}\text { Scale items } \\
\text { I would be willing to: }\end{array}$}} & \multicolumn{3}{c|}{ Factors } \\
\cline { 2 - 5 } & $\begin{array}{c}1 \\
\text { Resell }\end{array}$ & $\begin{array}{c}2 \\
\text { Reuse }\end{array}$ & $\begin{array}{c}3 \\
\text { Donate }\end{array}$ \\
\hline Resell old clothing to be more pro-environmental & $\mathbf{0 . 9 2 9}$ & 0.137 & 0.101 \\
\hline Resell old clothing to reduce environmental consequences & $\mathbf{0 . 9 1 7}$ & 0.138 & 0.157 \\
\hline Resell old clothing to be more sustainable & $\mathbf{0 . 8 9 5}$ & 0.091 & 0.138 \\
\hline Resell old clothing to reduce waste & $\mathbf{0 . 8 8 4}$ & 0.101 & 0.139 \\
\hline Reuse old clothing to reduce environmental consequences & 0.124 & $\mathbf{0 . 8 6 8}$ & 0.277 \\
\hline Reuse old clothing to be more sustainable & 0.105 & $\mathbf{0 . 8 6 3}$ & 0.269 \\
\hline Reuse old clothing to be more pro-environmental & 0.132 & $\mathbf{0 . 8 5 9}$ & 0.213 \\
\hline Reuse old clothing to reduce waste & 0.127 & $\mathbf{0 . 7 9 6}$ & 0.291 \\
\hline $\begin{array}{l}\text { Donate old clothing to reduce environmental } \\
\text { consequences }\end{array}$ & 0.119 & 0.265 & $\mathbf{0 . 8 9 4}$ \\
\hline Donate old clothing to be more sustainable & 0.112 & 0.258 & $\mathbf{0 . 8 7 1}$ \\
\hline Donate old clothing to be more pro-environmental & 0.136 & 0.266 & $\mathbf{0 . 8 1 4}$ \\
\hline Donate old clothing to reduce waste & 0.208 & 0.265 & $\mathbf{0 . 7 6 5}$ \\
\hline Standard deviation & 0.81 & 1.06 & 0.83 \\
\hline Cronbach Alpha & 0.94 & 0.96 & 0.94 \\
\hline
\end{tabular}

Despite the fact that respondents seem willing to dispose of their apparel in a proenvironmental manner (whether it be for the sake of the environment or other underlying reasons), most researchers agree that pro-environmental intent does not always imply that the consumer will engage in actual environmentally responsible behaviour [16]. Future research should thus focus on measuring actual behaviour by means of larger encompassing samples. Despite the difficulties of recruiting representative samples in emerging economies, such actions are important in achieving generalizable results, especially for developing countries such as South Africa that are characterised by heterogeneous consumer populations.

In conclusion, the quest for environmental preservation and sustainability is important and span across various types of consumer behaviour and products. In this regard, scientific efforts should be ongoing and relentless in its pursuit of gaining deeper and broader understanding of not only motivational aspects, but also other contextual factors that may ultimately influence consumers' disposal behaviour.

\section{ACKNOWLEDGEMENTS}

The financial assistance of the National Research Foundation (NRF) towards this research is hereby acknowledged. Opinions expressed and conclusions arrived at, are those of the author and are not necessarily to be attributed to the NRF. 


\section{REFERENCES}

[1] Intergovernmental Panel on Climate Change (IPCC), Climate Change 2014: Synthesis Report, Cambridge University Press: Cambridge, 2014.

[2] Hardoy, J.E., Mitlin, D. \& Satterthwaite, D., Environmental Problems in an Urbanizing World: Finding Solutions in Cities in Africa, Asia and Latin America, Earthscan Publications Ltd., 2013.

[3] Ecological Footprint, World Wide Fund for Nature (WWF). http://wwf.panda.org/about_our_earth/teacher_resources/webfieldtrips/ecological_ba lance/eco_footprint/. Accessed on: 17 Sep. 2016.

[4] Ogwueleka, T.C., Municipal solid waste characteristics and management in Nigeria. Iranian Journal of Environmental Health Science and Engineering, 6(3), pp. 173-180, 2009.

[5] Wilson, D.C., Development drivers for waste management. Waste Management and Research, 25(3), pp. 198-207, 2007. DOI: 10.1177/0734242x07079149.

[6] Muniafu, M. \& Otiato, E., Solid waste management in Nairobi, Kenya. A case for emerging economies. The Journal of Language, Technology and Entrepreneurship in Africa, 2(1), pp. 342-350, 2010. DOI: 10.4314/jolte.v2i1.52009.

[7] Hu, Z., Chen, Q.L. \& Wang, Y., Sustainable rent-based closed-loop supply chain for fashion products. Sustainability, 6(10), pp. 7063-7088, 2014.

DOI: $10.3390 /$ su6107063.

[8] Oketola, A.A. \& Osibanjo, O., Estimating sectoral pollution load in Lagos by industrial pollution projection system (IPPS). Science of the Total Environment, 377(2-3), pp. 125-141, 2007. DOI: 10.1016/j.scitotenv.2006.12.054.

[9] Bianchi, C. \& Birtwistle, G., Consumer clothing disposal behaviour: a comparative study. International Journal of Consumer Studies, 36(3), pp. 335-341, 2012.

DOI: 10.1111/j.1470-6431.2011.01011.x.

[10] Mor, S., Ravindra, K., Dahiya, R.P. \& Chandra, A., Leachate characterization and assessment of groundwater pollution near municipal solid waste landfill site. Environmental Monitor and Assessment, 118(1-3), pp. 435-456, 2006.

DOI: 10.1007/s10661-006-1505-7.

[11] Joung, H. \& Park-Poaps, H., Factors motivating and influencing clothing behaviours. International Journal of Consumer Studies, 37(1), pp. 105-111, 2013.

DOI: 10.1111/j.1470-6431.2011.01048.x.

[12] Meyer, J., The role of values, beliefs and norms in female consumers; clothing disposal behaviour. Unpublished Master's dissertation, University of Pretoria, 2013.

[13] Department of Environmental Affairs, National Waste Information Baseline Report, South Africa. http://sawic.environment.gov.za/documents/1880.pdf. Accessed on: 3 Aug. 2016.

[14] Solomon, M.R., Russell-Bennett, R. \& Previte, J., Consumer Behaviour, 3rd ed., Pearson Australia Group: Australia, 2013.

[15] Cho, E., Gupta, S. \& Kim, Y.K., Style consumption: Its drivers and role in sustainable apparel consumption. International Journal of Consumer Studies, 39(6), pp. 661-669, 2015. DOI: 10.1111/ijcs.12185.

[16] Steg, L., Bolderdijk, J.W., Keizer, K. \& Perlaviciute, G., An integrated framework for encouraging pro-environmental behaviour: The role of values, situational factors and goals. Journal of Environmental Psychology, 38, pp. 104-115, 2014.

DOI: 10.1016/j.jenvp.2014.01.002. 